\title{
Performance capacity of the health system workforce towards integrated leading-managing-and-governing practices in Ethiopia: with special reference to the application of factor analysis and ordinal logistic regression
}

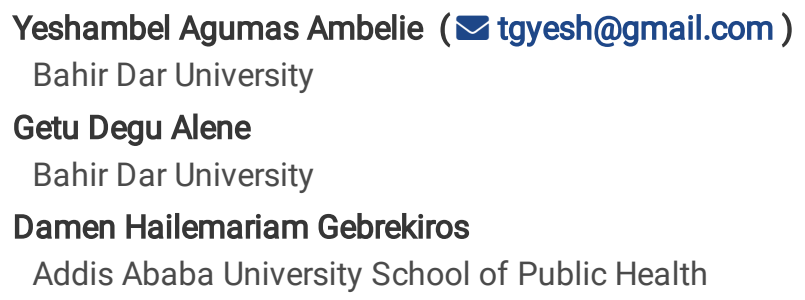




\section{Abstract}

Background Observing over-led and under-managed, over-managed and under-governed, and even out of these health organizations remains a common phenomenon in low and middle-income countries including Ethiopia. To balance these discrepancies, leadership and governance is regarded as the locus of all other critical health system building blocks. Thus, the current study looks at the performance capacity of the health system workforce towards integrated leading-managing-and-governing practices and its predictors in Ethiopia. Methods Eight-hundred-thirteen health system workforce were participated in this study. These were selected from 32 health care organizations located in northwest Ethiopia. Data were collected using a multi-item questionnaire. These data were fitted to factor analysis and ordinal logistic regression models. Factor analysis was used to develop scientifically reliable and empirically scalable measurement model. Once this model was tested for reliability and validity, the performance capacity of the health system workforce towards integrated leading-managing-and-governing practices (the outcome variable) was computed and labeled. Finally, ordinal logistic regression was conducted to model relationships between the outcome variable and its predictors using probability value and odds ratio. Results From 813 participants who rated the questionnaire, $396(48.7 \%)$ and 582 (71.6\%) were females and service owners respectively. Using these ratings, four factors were extracted. These factors together with items rated and error variances provided a four-factor measurement model. This model had estimates above .5, composite reliability above .7 and average variance extracted above .5. Using items in this model, the outcome variable was labeled as low (41.3\%), moderate (42.7\%), high (13.5\%) and very high (2.5\%). Sex and responsibility were among significantly associated predictors. Conclusions Empowering the health system workforce towards integrated leading-managing-and-governing practices using scientifically reliable and empirically scalable model is important, particularly in resource-limited settings. The policies and strategies developed in this regard should give due attention to females and service owners. The current results could provide foundations for training and future research. Trial registration The current study was part of a PhD dissertation research, which has been registered at clinical trials.gov since 9 July 2018 with identifiers: NCT03639961.

\section{Background}

Observing over-led and under-managed, over-managed and under-governed and even out of these health organizations remains a common phenomenon, particularly, in low and middle income countries[1]. This puzzle has been palpated in dealing with the successes, glitches and trends of health initiatives to ensure Universal Health Coverage (UHC) [2, 3].

Particularly, in driving the Millennium Development Goals (MDGs) that were in place from 2000 to 2015, diverse experiences were recorded from countries around the world[4, 5]. Reports show that many countries have made incredible achievements; some others made optimal improvements, and few with little progress[5]. These trends doubted the reachability of the goals in considerable number of countries.

This doubt unduly pressured the globe to sit for a strategy (2007) through the World Health Organization (WHO) [3, 6, 7]. As a result, leadership and governance is regarded as the locus of all other critical health system building blocks[8,9]. This is also underlined to be continuing as a locus in executing Sustainable Development Goal three (SDG-3) that is "ensure healthy lives and promote well-being for all at all ages"[10].

Currently, there is a promising signal in that the health system workforces at all levels look forward to applying scientifically reliable and empirically scalable integrated Leading-Managing-and-Governing $(L+M+G)$ practices[11-13]. Following this, though donor driven, many low and middle income countries including Ethiopia have launched an integrated $L+M+G$ practices capacity building package[11, 14]. Integrated health system $L+M+G$ practices can generally be stated as the process of influencing people for functioning tasks in an ethical and moral manner to improve and maintain societal health and well-being.

Although integrated health system $L+M+G$ has caught the attention of the health system workforce in considerable number of low and middle-income countries, yet, there has been dearth of attempts to develop or test scientifically reliable and empirically scalable integrated models of practices of the three paths[4, 13-15]. Some reasons can be mentioned to such dearth of attempts. First, since long ago, concepts of leadership[16, 17], management[18, 19] and governance[20, 21] have been seen as separate agencies. Second, preaching these paths as they belongs to an elite group of people who are naturally gifted, rather than discoursing as every ones job is another reason. Third, poor integration between the three worlds: civil service, academic sphere and research institute. Usually, the workforce residing in civil service focus on how to do it; those nesting in academic sphere emphasize on what it is, and those living within research institute stress on how to model it. Finally, it would be that the integration concept is donor driven, meaning it is not initiated from within. 
Studies indicate that the health system workforce capacity towards leading or/and managing or/and governing practices improves Key Performance Indicators (KPIs) $[1,13,22-26]$. Some other studies report that there is a significant duplication among the practices of the three dimensions ${ }^{[22,27]}$. Moreover, integrating distinctly put, but duplicated practices will be difficult unless the diverse $L+M+G$ practices are amalgamated meaningfully. This, in fact, needs rethinking and redesigning beyond the rhetoric $[25,28,29]$.

Thus, the current study levels the performance capacity of the health system workforce towards integrated $L+M+G$ practices and identifies predictors that affect it in northwest Ethiopia. This is done after developing and testing a measurement model, benchmarking the Management Science for Health (MSH) integrated health system $L+M+G$ practices framework[11, 14], illustrated in figure 1. This framework was developed in 2015[14], and has been introduced in many low and middle income countries including Ethiopia[4, 11, 14]. As indicated in figure 1, the model consists of twelve practices, of which four-practices are put parallels for leading, managing and governing paths in equidistant[28, 30,31]. Nonetheless, neither how these practices are correlated nor modeled is yet reported. Why do not people see it?

Generally, this may be due to the long-standing rhetoric that leading[16, 17], managing[18, 19] and governing[20, 21] are seen as distinct paths. The interruption power of this thought towards seeing soundly correlated and modeled $L+M+G$ practices can be exemplified with the problems that have been raised by considerable participants who have trained putting the above model at the locus in Ethiopia[4]. The problem can be summarized with two-fold: first, the model comprises numerous jargons which needs more investment on what it is, than how to do it; second, while the jargons can be understood with what is so ever investments, the issue of cross duplications among them are followed.

Thus, the results of this study could support to scheme scientifically reliable and empirically scalable capacity building policies and strategies towards performing integrated health system $L+M+G$ practices.

\section{Methods}

\section{Study design, participants and data collection}

This study, designed to be cross sectional, aimed at leveling the performance capacity of the health system workforce towards integrated $L+M+G$ practices and identifying its predictors. Eight hundred thirteen participants, aged 18 years and greater, were included in the current study. These were the health system workforce, selected from 32 health care organizations located in northwest Ethiopia. Data from these participants were collected using structured self-rated multi-item questionnaire. Each participant rated his or her respective staff capacity towards performing integrated $L+M+G$ practices. The process was strictly anonymous and questionnaires completed were stored in a locked cabinet.

\section{Measures}

Twenty-six items with five-point Likert scale were rated. The scales were ranged from $1=$ very low to $5=$ very high. The test stimuli (psychometric properties) of the questionnaire was refined through rigorous debriefing sessions. The debriefing was focused on instrument clarity, question wording and validity. Five specialists of health service management, of whom three were from civil service and two from the academic spheres were involved in reviewing the questions and wordings. The questionnaire was pre-tested on 42 participants working in similar settings but out of the actual study area. Finally, an item was retained only if there was an internal consistency, alpha value, of $80 \%$ or greater[32].

\section{Analysis}

Data were entered using Epi-demographic Information (Epi-Info) version 7 and analyzed using Statistical Package for Social Science SPSS version 22. In analyzing this data, different techniques such as descriptive, exploratory factor, composite reliability, average variance extraction and ordinal logistic regression were employed.

\section{Descriptive analysis}

Information about the socio-demographic characteristics of the participants, and the central tendency of the rated items was summarized with descriptive statistics.

\section{Exploratory factor analysis}


Exploratory Factor Analysis (EFA) was unlocked to assemble the relationship among factors extracted, items rated and error variances observed. Here, an item was the measured variable that is included in the data collection questionnaire; a factor was unobserved variable which typically could not be directly measured, but it was assumed to cause the observed scores on the item; and error variance was the portion of the factor that could not be predicted from the remaining factors.

About five data to model fit indices were tested: inter-correlation of .3 and greater, Kaiser-Meyer-Olkin (KMO) test of overall Measure of Sampling Adequacy (MSA) of . 5 and greater with Bartlett's test of sphericity $(P<.05)$, intra-item consistency of .7 and greater, total variance explained of $60 \%$ and greater, and communality of .5 and greater[33-35]. The communality represented proportion of each item's variance that can be explained by the factors $[34,36]$. Due to violating the rule of communality (table 3 ), two items were removed from the original 26 -item dataset and reduced it to a 24 -item dataset.

EFA with the these dataset was iterated to extract factors and to display factor loadings using principal axis factoring method with varimax rotation and a cut point of eigenvalue greater than 1. But, another four items (discussed somewhere else) were removed from the 24-item dataset, due to violating the rule of complex structure, that is, any factor had not been resided on more than one item with factor loadings of .4 and greater [33]. It showed that the dataset that satisfied the necessary requirements of factor analysis was reduced again to a 20-item dataset. From this dataset, the measurement model intended for leveling the performance capacity of the health system workforce towards integrated $L+M+G$ practices was developed. Moreover, to make this measurement model more meaningful, factors extracted were labeled considering the contents (scientific and empirical domains) of the items clustered within them[36-38].

\section{Composite reliability and average variance extraction}

Composite Reliability (CR) and Average Variance Extraction (AVE) were calculated to test the reliability and validity[39, 40] of the measurement model using excel 2016. The reliability of the model was tested with $\mathrm{CR}$, which was calculated from the squared sum of factor loadings divided by the squared sum of factor loadings and the sum of error variances[41]. To reaffirm the reliability of the model the CR was triangulated with the total variance explained. Whereas, the validity of the model was tested using the AVE, which was triangulated with factor correlations. The AVE was calculated from sum of factor loading squared divided by sum of factor loading squared and sum of error variances[42]. The squared root of AVE was also considered, by which the presence of validity was supported if this value was greater than most of the correlation coefficients of items clustered within its own factors. Correlations were also tested whether they were significantly different from zero, which supported convergent validity; or the higher number of times that the item highly correlated within its own factor compared with the items of the other factors, that in fact covered the divergent validity. Here, the percent of variability that the items shared was determined by squaring the correlations between items and multiplied by 100 . Generally, the rule is that items should relate more strongly to their own factor than to another factor.

\section{Labeling the performance capacity of the health system workforce}

The performance capacity of the health system workforce towards integrated $L+M+G$ practices was computed from the 20 items indicated on the measurement model (figure 2). This again was leveled into four ordinal categories, which were labeled as low, moderate, high and very high that represented scores of $<60,60-79.99,80-94.99$ and $\geq 95$ respectively, which based the performance appraisal guideline in Ethiopia (un published document).

\section{Ordinal logistic regression analysis}

Ordinal Logistic Regression Analysis (OLRA) with logit link function was conducted to model the relationship between the performance capacity of the health system workforce towards integrated $L+M+G$ practices and its predictors: socio-demographic characteristics and items trimmed from factor analysis. Model fitting information that was tested by (-2Log Likelihood) was significant at $p<.001$. Besides, the consistency of the observed data tested with Pearson chi-square goodness-of-fit was remained satisfactory with $p=1$. In addition, the explained variance of the outcome variable from the predictors was tested by pseudo r-squared value (Nagelkerke's $\mathrm{R}^{2}=.765$ ), which indicated strong association. Moreover, the test of parallel lines or testing proportional odds assumption that is testing whether the location parameters (slope coefficients) of predictors were the same across outcome variable categories was tested by (-2Log Likelihood, and became non-significant with Probability value $(P)=.487$. This showed that the slope coefficients were the same across response categories, which told that there had no evidence to reject the parallelism hypothesis. Finally, to interpret the impact of individual predictors in a better way, odds ratios with $95 \%$ Confidence Intervals (Cls) were calculated from the odds. 


\section{Results}

\section{Socio-demographic characteristics of participants}

Table 1 presents the participants socio-demographic characteristics. From 813 participants, $396(48.7 \%)$ were females and $582(71.6 \%)$ were service owners. Their mean ( \pm standard deviation) age was $29( \pm 5)$ years. The ages were ranged from 18 to 56 years.

\section{Indices test of measuring items}

Table 2 indicates the means $(\bar{x})$, standard deviations (s), and correlations ( $r$ ) of measuring items. The means and standard deviations were included to show the central tendencies together with the corresponding dispersions as part of the descriptive statistics.

The inter-correlations presented on the off diagonal part of the table ranged from .328 to .812 . When each correlation is squared and multiplied by 100 , it determines the percentage of variability that the respective two variables shared. For example, when the coefficient .328 that is the coefficient between item "12" (row) and item " 1 " (column) is squared, it becomes .108, and when multiplied by 100 , it is $10.8 \%$. This shows that the two items shared $10.8 \%$ of the variability each other.

Likewise, the correlations indicated on the diagonal section of the table were the correlations of the individual items with itself, which often gives the value of one, telling perfect correlation.

Table 3 presents other tests of indices for the dataset that is internal consistency and communality. The MSA for individual items, which is displayed on the off diagonal part of the table were .936 and greater; the overall MSA was also .962 with $(\mathrm{P}<.001)$.

Considering the communalities, which are indicated at the last column of table 3, particularly values on the off bracket, two items: (1) set annual and strategic organizational plan with (communality = .470); and (2) allocate adequate resources for work with (communality $=.498$ ) were violated the statistically recommended cutoff point. Respecting the rule of thumb that is removing a single item with a minimum value at a time, a series of factor analysis was run until all the items had a communality of .5 and greater. Thus, by removing "set annual and strategic organizational plan"; and iterated the analysis, the communality for "allocate adequate resources for work became .481. The analysis was iterated eliminating it, and at this point the output, particularly presented within the bracket, showed that the remained items had communality .5 and greater. At this stage, the original 26 -item dataset was reduced to a 24 -item dataset.

\section{Factor extraction}

Table 4 displays the variance explained by the initial solution, extracted factors and rotated factors. In all the three sections of the table, the total column reports the amount of variance, or the eigenvalue in the original items accounted for by each factor. The percent of variance column contained the percent of total variance accounted for by each factor. Finally, the cumulative percent column contained the cumulative percentage of variance accounted for by the current and preceding factors.

The first section of table 4 indicates the initial eigenvalues or the variances of the factors. For the initial solution, there are as many factors as items, and in correlation analysis, items were standardized, to mean that each item had a variance of 1 , and the sum of the eigenvalues equals the number of factors. The eigenvalues greater than 1 were taken as the cutoff point. Accordingly, the first four factors were extracted, accounting for $68.434 \%$ of the total variance.

The second section of table 4 presents the extraction sums of squared loadings. The number of rows in this section of the table correspond to the number of factors retained. In the current case, four factors were retained; thus, there were only four rows in this section of the table. The values in this section of the table were calculated in the same way as the values in the initial eigenvalue section, except that here the values were based on the common variance. These values were lower than the values in the initial eigenvalue section, because they were based on common variance, which is always smaller than total variance.

The third section of table 4 shows rotation sums of squared loadings. The values in this section of the table represent the distribution of the variance after rotation. The rotation maximized the variance of each of the factors, so the total amount of variance accounted for was redistributed over the four extracted factors. For example, before rotation factor 1 accounted for considerable level of variance than the other three that is $52.612 \%$ compared to $6.596 \%, 5.070 \%$ and $4.156 \%$ move from factor 2 to factor 4 , but when rotated, it accounted for only $20.572 \%$, compared to $15.771 \%, 13.798$ and $12.716 \%$ respectively. 


\section{Factor loadings}

Table 5 provides factor loadings and communality values of the 20-item dataset. This was displayed after trimming another four items that violated the rule of complex structure.

Firstly, "provide appropriate feedback to other organization members" with factor loadings of .446 and .544 within factors 1 and 2; and "look for best practices in the last 12 months" with factor loadings of .415 and .522 contained by factors 3 and 4 respectively.

Secondly, "match deeds to words" with factor loadings of .508 and .457 within factors 2 and 4; and "develop a structure that provide accountability and authority" with factor loadings of .405 and .607 enclosed within factors 2 and 3, respectively.

In the factor loadings table, unless the coefficients .4 and less were suppressed to emphasize that which factor was highly loaded on a specific item, other ways all the factors had a loading on each item. Perhaps, if each loadings was displayed, it could be supportive to check the communality of each item manually[34], which was displayed in the last column of the table. Likewise, unless factor loadings were sorted by size, other ways the table could also be presented differently.

\section{Factor labeling}

The four factors extracted were labeled considering the contents (scientific and empirical domains) of the items clustered within each of them[36-38]. As indicated on table 5, the eight items that loaded highly on factor 1 seemed to value the different aspects of organizational principles. Thus, this factor was labeled as compliance with principles. Besides, the four items that loaded highly on factor 2 contained diverse characteristics of strategy. Hence, it was termed as strategic sensitivity. Additionally, another four items that loaded highly on factor 3 appeared to correlate to various features of system development. Then, it was named as system building. Finally, the remaining four items that loaded highly on factor 4 gave the impression to relate to context. Accordingly, it was called as contextual thoughtfulness.

\section{A four-factor measurement model}

Figure 2 indicates the four-factor measurement model. Observing the figure from left to right, the lines rayed from performance capacity of the health system workforce towards integrated $L+M+G$ practices denote the factors extracted. The lines radiated from each factor towards the item represent the degree of correlation of each item with the corresponding factor. The lines reflected against each item symbolize the error variance. These variances were calculated from one minus communality (values in the last column of table 5), which explained the portion of each observed item that was not predicted from the factors. The higher error variance (.5 and greater) indicated that an item might not belong to any factor.

\section{Reliability and validity test}

Table 6 presents the Composite Reliability (CR), and Average Variance Extraction (AVE) of each factor. For example, the CR for compliance with principles is .921, which could be interpreted that the reliability of this factor in the measurement model was $92.1 \%$; and the AVE for it was .598, which means that it explained $59.8 \%$ of the variance of the corresponding items in the measurement model.

\section{Levels of performance capacity towards integrated $L+M+G$ practices}

Figure 3 indicates the levels of performance capacity of the health system workforce towards integrated $L+M+G$ practices. For instance, about $41.3 \%$ of the health system workforce had low level of performance capacity towards integrated $L+M+G$ practices.

\section{Predictors of performance capacity towards integrated $L+M+G$ practices}

Table 7 displays estimated coefficients of the ordinal logistic regression model. The estimates labeled "threshold" indicated that where the latent variable was cut to make the groups that were observed in the table, other ways it was not used in the interpretation of the results.

The other estimates labeled "location" were the ones that the researchers interested in, which were the coefficients (odds) of the predictors.

To interpret the impact of individual predictors in a better way, proportional odds ratio with $95 \% \mathrm{Cl}$, for each categories of predictors were calculated by coefficient exponentiation, which were indicated in the exponential (EXP) column of table 7. From the observed 
significance levels: sex and responsibility were significantly related $(P<.05)$ to the levels of performance capacity of the health system workforce towards integrated $L+M+G$ practices, whereas, age, educational level and service year were appeared non-significant $(P>05)$. For example, the odds ratio of male health system workforce was $1.502(95 \% \mathrm{Cl}, 1.038$ to 2.173$)$; which could be interpreted as being male health system workforce was $50.2 \%$ higher to perform integrated $L+M+G$ practices in a very high level compared with those of females $(p=.031)$, holding all other predictors in the model constant. Furthermore, all the six items that were trimmed from the measurement model and treated as predictors were significantly related to the levels of performance capacity $(p<.05)$.

For instance, the odds ratio of the health system workforce who had very low rate of 'look for best practices in the last 12 months' was $.029(95 \% \mathrm{Cl}, .011$ to .080$)$. This could be inferred as very low rate of "look for best practices in the last 12 months", reduced the workforces' higher level of performance capacity towards integrated $L+M+G$ practices by $97.1 \%$ compared with very high rate of it $(P=$ .000), holding all other variables in the model constant.

\section{Discussion}

The current study levels the performance capacity of the health system workforce towards integrated $L+M+G$ practices. It also identifies predictors related with this performance capacity. These are done after developing and testing a four-factor measurement model.

This measurement model provided from a study done in Ethiopia can catch the attentions of the health system workforce at all levels, particularly in low and middle-income countries $[4,11,12,14]$. In fact, the workforce in such countries are assigned to ensure UHC in an increasingly socially, politically, economically and technologically turbulent ecosystem $[4,5]$. These turbulences might be overcome by empowering the health system workforce towards integrated $L+M+G$ practices, using scientifically reliable and empirically scalable models.

This concept is supported by some studies, which report that capacitating the health system workforce with the 12-practice integrated L+M+G framework improves the Key Performance Indicators (KPIs) of health services[22-25]. Nevertheless, few other studies report that there exists significant duplications among the practices assembled in the 12-practice framework[22, 28]. This might emanate, on one hand, from the rhetoric that accounts these paths as separate[17, 18, 21], and on the other hand, from the lack of using statistically reasonable techniques in modeling the 12-practice framework.

Thus, the current study answers the existing gaps in modeling integrated leading-managing-and-governing practices, through three main actions. Firstly, these authors collected the data using the multi-item questionnaire that incorporates a representative number of items from the three none hostile paths. Secondly, they employed a statistically reasonable technique that is factor analysis with varimax rotation in extracting factors. Finally, they developed a measurement model by assembling these four factors together with the items rated and error variances observed.

In the meantime, to make this measurement model more meaningful, the four factors extracted (table 5) are labeled based on the contents that the factor loadings reflect[36-38]. The first factor is named as compliance with principles. The word compliance describes act of acquiescing with a set of rules and the term principle explains accepted rule of action. Thus, compliance with principles could be stated as ability to act with accepted set of rules. The second factor is labeled as strategic sensitivity. Here, strategic describes mindfulness about mission and vision and sensitivity refers to strong attention. Hence, strategic sensitivity might be operationalized as intensity of mindfulness towards mission and vision[43]. Likewise, the third factor is termed as system building. System means group of interdependent components that form unified whole[14] and building refers to improving interactions among the components. Therefore, system building might possibly referred as ongoing process of improving interaction among the components. The final factor is denoted as contextual thoughtfulness. The term contextual refers to state of exploring conditions regarding to the environment and the word thoughtfulness describes deliberate thinking before doing something. Accordingly, contextual thoughtfulness can be defined as deliberate thinking in exploring conditions regarding to the environment.

The measurement model is also tested for reliability and validity through the values of CR and AVE (table 6) respectively, which in general show that groups of items assembled in the model are nicely loaded. In addition to the CR, the reliability of the model is checked with the total variance explained (table 4), in that the value for the first factor is quite larger than the next factor [41]. Similarly, the validity of the model that is the variance is due to the construct, but not due to the measurement error is reaffirmed with the correlation coefficients (table 2), besides the AVE. At this point, the correlations are significantly different from zero showing convergent validity, and the items are highly correlated with higher number of times within their own factor compared with the items of the other factors demonstrating divergent validity[39, 40, 42, 44]. 
Generally, the current measurement model is acceptable in that: all estimates sound well, all estimates are above .5, CR for all factors is above .7, the total variance for the first factor is quite larger, AVE for all factors is above .5, and items are highly correlated with higher number of times within their own factor.

As noted earlier, the current study levels the performance capacity of the health system workforce towards integrated $L+M+G$ practices as low, moderate, high, and very high. This leveling base the categories that are indicated in the health system workforce performance appraisal guideline of Ethiopian.

Though limited in scope, some studies report that the health system workforce capacity towards leading or/and managing or/and governing practices improves the health service outcomes[1, 12, 22, 23, 26, 27]. Nevertheless, these studies would not report levels of capacity, as well as, the degree of considering the three paths in assessing it. These might be due to the belief that leadership, management and governance have been accounted for a small number of actors, perhaps only those who are legally authorized; and the dearth of representative integrated models respectively. These indicate that there should be a breakthrough that shows the importance of performing the three paths in an integrated way, using scientifically reliable and empirically scalable models, by recalling that the entire reason being human is leadership or ruler-ship regardless of situations and hierarchies[45].

The current study also models the relationship between the outcome variable and its predictors including socio-demographic characteristics, by employing ordinal logistic regression (table 7). Sex and responsibility, as well as, the six items treated as predictors such as: (1) look for best practices in the last 12 months; (2) match deeds to words; (3) set annual and strategic organizational plan; (4) allocate adequate resources for work; (5) develop a structure that provide accountability and authority; (6) provide appropriate feedback, are significantly related. Whereas, age, educational level and service year are appeared insignificant.

Though, few literatures hypothesize determinants (measuring items) for each of leadership, management and governance separately[18, 20,46], yet, how they are correlated and modeled, even within the respective path, have not been tested and reported.

Regarding to leadership, among many contributors, Richard Denny in his book reports 12 determinants: level of organizing details, the stand of the people to do what they would ask another to do, expectation of what people paid for, perception towards colleagues, level of creativity, self-perception, indulgence, level of loyalty, leadership approach, title and expertise, environment, and common sense[46].

Likewise, Henri Fayol reports about 14 determinant principles of management: division of work, authority and responsibility, discipline, unity of command, unity of direction, subordination of individual interest, remuneration, the degree of centralization, scalar chain, order, equity, stability of tenure of personnel, initiative and esprit de corps[18].

Moreover, a synthesis paper on effective governance for health revealed 10 determinants of governance: leadership, corruption, management, transparency, accountability, systems to manage data, participation of key stakeholder, political context, check and balance strategy, and financial resources[20].

The above exemplifications clearly show that one path is even accounted as determinant for the other path. For instance, leadership and management are mentioned as determinants of governance. Additionally, regardless of the level of specificity, most-perhaps-all of the characteristics mentioned as determinants in one path have a twin concept in the other paths. For example, common sense, unity of direction, and participation of stakeholder are similar concepts, but mentioned as determinants of different paths. This is the other reason, in that the current study develops and tests the above mentioned four-factor measurement model, considering representative items from each path.

Moreover, other than used as hypotheses, the report of the above and the like literatures would be helpless. Particularly, when people or organizations need to develop capacity building policies and strategies based on socio-demographic characteristics, in which their relationships with the outcome variable are nevertheless modeled. Hence, to illustrate the gap and provide a founding information, the current study models the relationships between the outcome variable and its predictors, particularly socio-demographic characteristics. For instance, being male workforce has a higher performance capacity towards integrated $L+M+G$ practices compared with female workforce (table 7). This deviation might be arose from that, limited number of females are legally authorized to lead, manage and govern organizations, mainly in developing countries including Ethiopia. In such countries, this has a historical trend, in which breaking it and bringing adequate number of females to the stage is a troublesome investment. However, almost $50 \%$ of the participants in this study are females, which might indicate that considerable number of the workforce in the health facilities are females. Thus, whatever 
reasons people have, without empowering half of the segment of the workforce towards integrated $L+M+G$ practices, getting organizations to the intended stage would be rather impossible.

The other significantly associated predictors (most at $P=.000$ ) as indicated in table 7 are the six items that are trimmed from factor analysis, and fitted to ordinal logistic regression analysis. This implies that, in scheming capacity building policies and strategies, as well as, designing further research, nesting them within the biologically plausible factor would be more meaningful. For example, among the six items that are significantly related with the outcome variable in the current study: item 1 can be captured by contextual thoughtfulness; item 2 can be enclosed within strategic sensitivity, items 3, 4 and 5 can be nested within system building, and item 6 can be contained by compliance with principles.

Away from all the implications, the dearth of available literatures that either develop or test integrated measurement model, level the performance capacity of the health system workforce towards integrated $L+M+G$ practices and identify predictors, particularly sociodemographic characteristics that affect it, had limited the depth of our discussion.

\section{Conclusions}

Empowering the health system workforce towards integrated leading-managing-and-governing practices is important, particularly in resource-limited settings. The policies and strategies in this regard should give due attention to females and service owners. These policies and strategies should also consider the current four-factor measurement model, which is developed using a statistically recommended model, factor analysis.

The current results could provide foundations for future research and training. Feature research should be done taking into consideration: hierarchical variables, mixed design and participants from different countries.

\section{Abbreviations}




\begin{tabular}{|c|c|}
\hline AVE & Average Variance Extraction \\
\hline BDU & Bahir Dar University \\
\hline BSC & Balance Score Card \\
\hline $\mathrm{Cl}$ & Confidence Intervals \\
\hline CR & Composite Reliability \\
\hline EFA & Exploratory Factor Analysis \\
\hline Epi-Info & Epi-demographic Information \\
\hline EXP & Exponential \\
\hline $\mathrm{FMoH}$ & Federal Ministry of Health \\
\hline KPIs & Key Performance Indicators \\
\hline $\mathrm{KMO}$ & Kaiser-Meyer-Olkin \\
\hline$L+M+G$ & Leading, Managing and Governing \\
\hline MDGs & Millennium Development Goals \\
\hline MSA & Measure of Sampling Adequacy \\
\hline MSH & Management Science for Health \\
\hline OR & Odds Ratio \\
\hline ORLA & Ordinal Logistic Regression Analysis \\
\hline SDG-3 & Sustainable Development Goal-3 \\
\hline SPSS & Statistical Package for Social Science \\
\hline$P$ & Probability value \\
\hline PhD & Doctor of Philosophy \\
\hline UHC & Universal Health Coverage \\
\hline WHO & World Health Organization \\
\hline
\end{tabular}

\section{Declarations}

\section{Ethics approval and consent to participate}

Ethical clearance was secured from Bahir Dar University (BDU) with a protocol number 090/18-04, and written consent was obtained from each participant.

Consent for publication: Not applicable.

Availability of data and material

Data and materials have been available from the corresponding author, which upon reasonable request and the permission of BDU will be released.

\section{Competing interests}

All the authors declare that they have no competing interests.

\section{Funding}

BDU funded the research. It had no role in the design of the study and collection, analysis, and interpretation of data and in writing the manuscript. 
YA pictured the original idea, designed the study and participated in all performance stages of the project; analyzed the data and finalized to write the manuscript.

GD pictured the original idea, designed the study and participated in all performance stages of the project; analyzed the data and finalized to write the manuscript.

DH pictured the original idea, designed the study and participated in all performance stages of the project; analyzed the data and finalized to write the manuscript.

All authors reviewed and approved the final manuscript.

\section{Acknowledgements}

Our special thanks and sincere appreciation go to the study participants, data collectors, and data supervisors, for their respective valuable contribution. Our gratitude also extend to BDU for funding this study, which is part of a PhD dissertation research.

\section{Authors' information}

YA, a Public Health PhD candidate, is the lecturer of health service management in BDU. He has also done research, and delivered community services.

GD is a professor of Public Health at Bahir Dar University. He has published many researches and delivered considerable number of community services.

DH is a professor of Public Health and Health Economics at Addis Ababa University. Likewise, he has published many researches and delivered considerable number of community services.

\section{References}

1. Fetene N, Canavan ME, Megentta A, Linnander E, Tan AX, Nadew K, Bradley EH: District-level health management and health system performance. PloS one 2019, 14(2):e0210624.

2. World Health Organization: The world health report 2006: working together for health: World Health Organization; 2006.

3. Frenk J: Reinventing primary health care: the need for systems integration. The Lancet 2009, 374(9684):170-173.

4. Federal Ministry of Health: Leadership Management \& Governance In-Services Training Manual. 2017.

5. World Health Organization: Everybody's business-strengthening health systems to improve health outcomes: WHO's framework for action. 2007.

6. Van Lerberghe W: The world health report 2008: primary health care: now more than ever: World Health Organization; 2008.

7. World Health Organization: From alma Ata to the year 2000: reflections at the midpoint. 1988.

8. Vriesendorp S, De La Peza L, Perry C, Seltzer J, ONeil M: Health systems in action: an ehandbook for leaders and managers. 2010.

9. Daire J, Gilson L, Cleary S: Developing leadership and management competencies in low and middle-income country health systems: a review of the literature. Cape Town: Resilient and Responsive Health Systems (RESYST) 2014.

10. World Health Organization: World Health Statistics 2016: Monitoring Health for the SDGs Sustainable Development Goals: World Health Organization; 2016.

11. Galer JB, Vriesendorp S, Ellis A: Managers who lead: a handbook for improving health services. 2005.

12. DeRue DS, Myers CG: Leadership development: A review and agenda for future research. Oxford handbook of leadership and organizations 2014:832-855.

13. Martineau T, Raven J, Aikins M, Alonso-Garbayo A, Baine S, Huss R, Maluka S, Wyss K: Strengthening health district management competencies in Ghana, Tanzania and Uganda: lessons from using action research to improve health workforce performance. BMJ global health 2018, 3(2):e000619.

14. Management Sciences for Health. Rice JA, Shukla, Mahesh, Johnson Lassner, Karen et al.: Leaders Who Govern. June 2015. 2015.

15. Benowitz E: Cliffsquickreview Principles of management: Houghton Mifflin Harcourt; 2001.

16. Adair JE: Action-centred leadership: McGraw-Hill New York; 1973.

17. Bennis W: The leadership advantage. Leader to leader 1999, 12(2):18-23. 
18. Fayol H: Principles of management. URL: http://www grandars ru/college/ekonomika-firmy/anri-fayol html (accessed: October 20, 2015).

19. Drucker P: The frontiers of management: Routledge; 2012.

20. Rice JA: Synyhesis paper effective governance for health 2012.

21. Elliott JE: Karl Marx: Founding Father of Workers' Self-Governance? Economic and Industrial Democracy 1987, 8(3):293-321.

22. Smith PC, Anell A, Busse R, Crivelli L, Healy J, Lindahl AK, Westert G, Kene T: Leadership and governance in seven developed health systems. Health policy (Amsterdam, Netherlands) 2012, 106(1):37-49.

23. La Rue KS, Alegre JC, Murei L, Bragar J, Thatte N, Kibunga P, Cheburet S: Strengthening management and leadership practices to increase health-service delivery in Kenya: an evidence-based approach. Human resources for health 2012, 10(1):25.

24. Mansour M, Mansour JB, El Swesy AH: Scaling up proven public health interventions through a locally owned and sustained leadership development programme in rural Upper Egypt. Human Resources for Health 2010, 8(1):1.

25. Mathauer I, Imhoff I: Health worker motivation in Africa: the role of non-financial incentives and human resource management tools. Human resources for health 2006, 4(1):24.

26. Prashanth N, Marchal B, Kegels G, Criel B: Evaluation of capacity-building program of district health managers in India: a contextualized theoretical framework. Frontiers in public health 2014, 2:89.

27. Uneke CJ, Ezeoha AE, Ndukwe CD, Oyibo PG, Onwe FD: Enhancing leadership and governance competencies to strengthen health systems in Nigeria: Assessment of organizational human resources development. Healthcare Policy 2012, 7(3):73.

28. Levey S, Vaughn T, Koepke M, Moore D, Lehrman W, Sinha S: Hospital leadership and quality improvement: rhetoric versus reality. Journal of Patient Safety 2007, 3(1):9-15.

29. Rauscher M, Walkowiak H, Djara MB: Leadership, Management, and Governance Evidence Compendium. 2018.

30. Bass BM, Stogdill RM: Bass \& Stogdill's handbook of leadership: Theory, research, and managerial applications: Simon and Schuster; 1990.

31. Kouzes J, Posner B: An instructor's guide to the leadership challenge. In.: San Francisco: Jossey-Bass; 1995.

32. Avolio BJ, Bass BM, Jung DI: Re-examining the components of transformational and transactional leadership using the Multifactor Leadership. Journal of occupational and organizational psychology 1999, 72(4):441-462.

33. Starkweather J: Principal Components Analysis vs. Factor Analysis... and Appropriate Alternatives. Available in original form at Benchmarks: http://it unt edu/benchmarks 2010(2010/07).

34. Beaumont R: An introduction to principal component analysis \& factor analysis using SPSS 19 and R (psych package). Factor Analysis and Principal Component Analysis (PCA) 2012, 24(8-9).

35. Osborne JW, Costello AB, Kellow JT: Best practices in exploratory factor analysis. Best practices in quantitative methods 2008:8699.

36. Comrey AL, Lee HB: A first course in factor analysis: Psychology Press; 2013.

37. Lolli S, Di Girolamo P: Principal component analysis approach to evaluate instrument performances in developing a cost-effective reliable instrument network for atmospheric measurements. Journal of Atmospheric and Oceanic Technology 2015, 32(9):1642-1649. 38. Field A: Factor analysis using SPSS. Retrieved March 2005, 17:2009.

39. C. Fornell and D. F. Larcker: Evaluating structural equation models with unobservable variables and measurement error. Journal of marketing research 1981:39-50,.

40. Campbell DT, Fiske DW: Convergent and discriminant validation by the multitrait-multimethod matrix. Psychological bulletin 1959 , 56(2):81.

41. Raykov T: Estimation of composite reliability for congeneric measures. Applied Psychological Measurement 1997, $21(2): 173-184$.

42. Alarcón D, Sánchez JA, De Olavide U: Assessing convergent and discriminant validity in the ADHD-R IV rating scale: User-written commands for Average Variance Extracted (AVE), Composite Reliability (CR), and Heterotrait-Monotrait ratio of correlations (HTMT). In: Spanish STATA Meeting: 2015; 2015.

43. Doz YL, Kosonen M: Embedding strategic agility: A leadership agenda for accelerating business model renewal. Long range planning 2010, 43(2-3):370-382.

44. Fornell C, Larcker DF: Structural equation models with unobservable variables and measurement error: Algebra and statistics. In.: SAGE Publications Sage CA: Los Angeles, CA; 1981.

45. Vos G: Biblical theology: old and new testaments: Wipf and Stock Publishers; 2003.

46. Denny R: Motivate to win: how to motivate yourself and others: Kogan Page Publishers; 2006. 


\section{Tables}

Table 1 Socio-demographic characteristics of participants $(n=813)$

\begin{tabular}{llcc}
\hline Variables & Categories & Frequency & Percent \\
\hline \multirow{4}{*}{ Sex } & Male & 417 & 51.3 \\
& Female & 396 & 48.7 \\
\cline { 2 - 4 } & 18-24 years & 124 & 15.3 \\
\cline { 2 - 4 } 25-29 years & 334 & 41.1 \\
\cline { 2 - 4 } & 30-34 years & 256 & 31.5 \\
\cline { 2 - 4 } Educational level Diploma and less & 99 & 12.2 \\
\cline { 2 - 4 } & First degree & 363 & 44.6 \\
\cline { 2 - 4 } & Second degree and above & 411 & 50.6 \\
\hline \multirow{2}{*}{ Responsibility } & Head of office & 61 & 4.8 \\
\cline { 2 - 4 } & Process owner & 35 & 4.3 \\
\cline { 2 - 4 } & Unit coordinator & 135 & 16.6 \\
\cline { 2 - 4 } & Service owners & 582 & 71.6 \\
\hline \multirow{2}{*}{ Year of service } & $<2$ years & 209 & 25.7 \\
\cline { 2 - 4 } & 2-4 years & 222 & 27.3 \\
\cline { 2 - 4 } & 5-8 years & 283 & 34.8 \\
\cline { 2 - 4 } & >8 years & 12.2 \\
\hline
\end{tabular}

Table 2 Means, Standard Deviations and correlations of items $(n=813)$ 


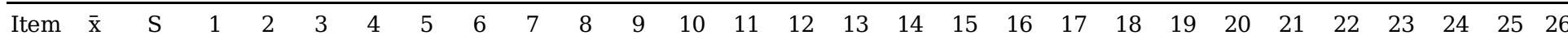

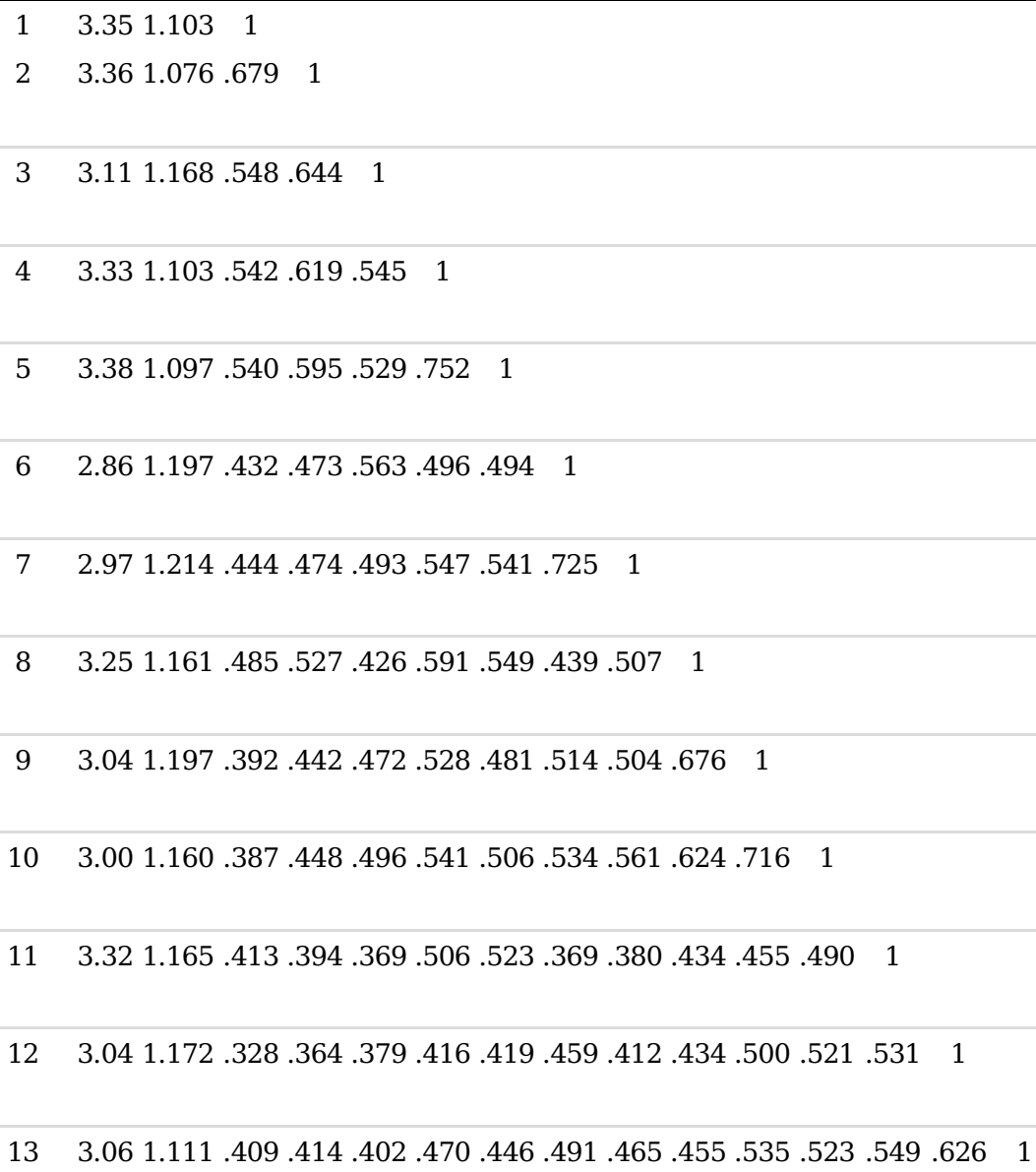


Note: The numbers from 1 to 26 represented: 1 = Identify client and stakeholder needs and priorities; $2=$ Recognize trends, opportunities, and risks; $3=$ Look for best practices in the last 12 months; $4=$ Articulate the organization's mission, strategy and vision; $5=$ Determine key priorities for action; $6=$ Enlist stakeholders to commit resources; $7=$ Unite mobilized resources to reach organizational vision; $8=$ Match deeds to words; 9 = Show trust and confidence and acknowledge contributions; $10=$ Model of creativity, innovation and learning; 11 = Set annual and strategic organizational plan; 12 = Allocate adequate resources for work; $13=$ Develop a structure that provide accountability and authority; 14 = Considers the organizational lines of authority for delegation; $15=$ Integrate work structures and work flow; 16 = Coordinate practices with other staff's programs; $17=$ Monitor their achievements against the plan, and take lessons; $18=$ Provide appropriate feedback to other organization members; $19=$ Uphold ethical and moral integrity to serve the public interest; $20=$ Establish a consultation mechanism to heard public voice; 21 = Ensure participation of key stakeholders; $22=$ Establish alliances for joint action at all levels; 23 = Oversee a shared direction to achieve organizational mission; $24=$ Advocate organizational mission and vision to stakeholders; 25 = Use resources in a way that maximizes the public well-being; and $26=$ Describe the outcomes related to the allocated resources.

Table 3 Internal consistencies and communalities of items $(n=813)$

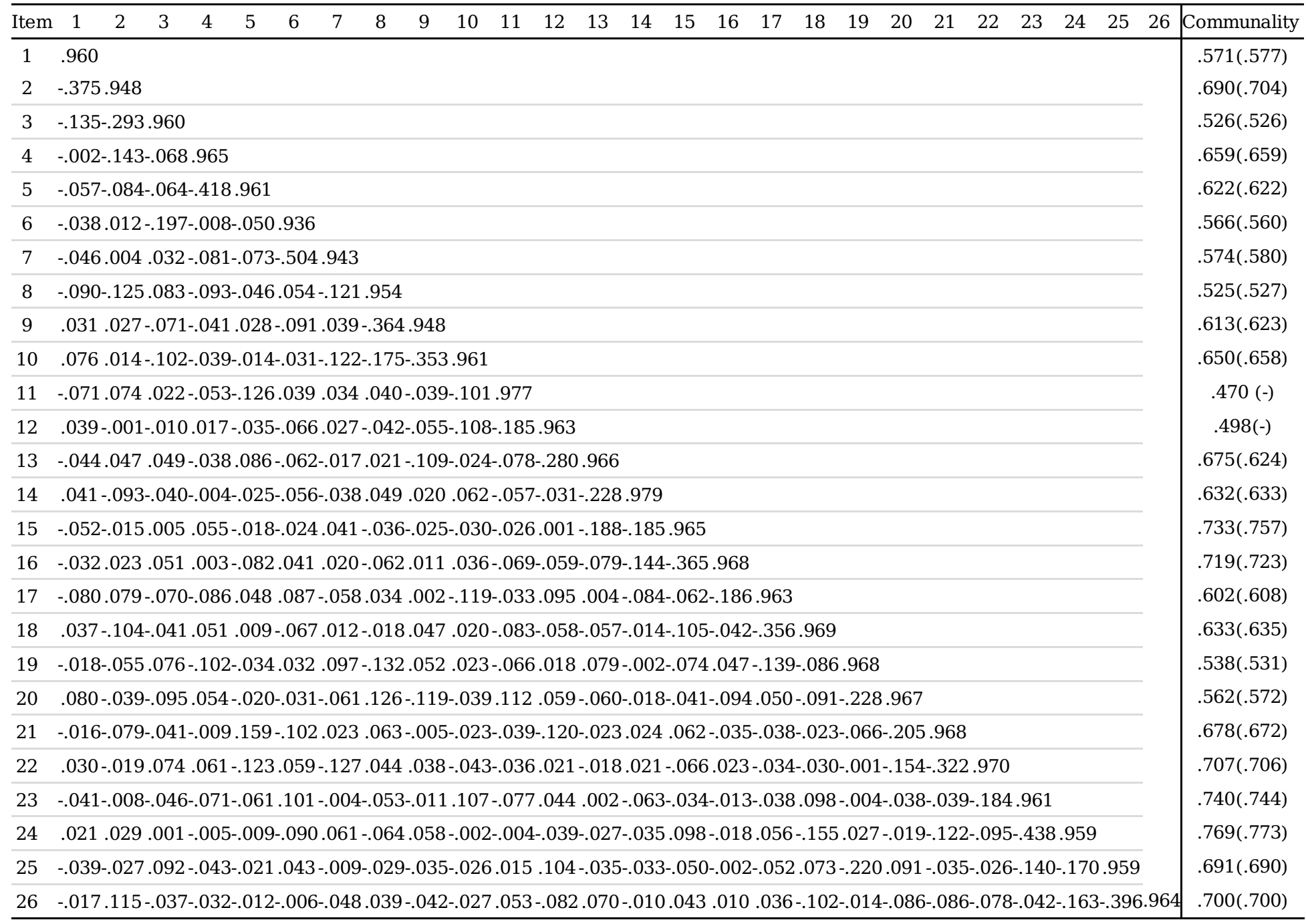

Note: - The numbers from 1 to 26 represented the same items explained in the footnote of table 2.

-The KMO test of overall MSA with Bartlett's test of sphericity was .962 $(P<.001)$

Table 4 Total variance explained by the initial solution, extracted factors and rotated factor $(n=813)$ 


\begin{tabular}{|c|c|c|c|c|c|c|c|c|c|}
\hline \multirow[b]{2}{*}{ Component } & \multicolumn{3}{|c|}{ Initial Eigenvalues } & \multicolumn{3}{|c|}{ Extraction Sums of Squared Loadings } & \multicolumn{3}{|c|}{ Rotation Sums of Squared Loadings } \\
\hline & $t^{\text {Total }}$ & $\%$ of Variance & Cumulative \% & Total & $\%$ of Variance & Cumulative \% & Total & $\%$ of Variance & Cumulative \% \\
\hline 1 & 13.679 & 52.612 & 52.612 & 13.316 & 51.214 & 51.214 & 5.349 & 20.572 & 20.572 \\
\hline 2 & 1.715 & 6.596 & 59.208 & 1.357 & 5.221 & 56.435 & 4.100 & 15.771 & 36.343 \\
\hline 3 & 1.318 & 5.070 & 64.278 & .963 & 3.705 & 60.140 & 3.587 & 13.798 & 50.141 \\
\hline 4 & 1.081 & 4.156 & 68.434 & .706 & 2.717 & 62.857 & 3.306 & 12.716 & 62.857 \\
\hline 5 & .927 & 3.564 & 71.999 & & & & & & \\
\hline 6 & .702 & 2.698 & 74.697 & & & & & & \\
\hline 7 & .622 & 2.391 & 77.088 & & & & & & \\
\hline 8 & .559 & 2.148 & 79.237 & & & & & & \\
\hline 9 & .491 & 1.887 & 81.124 & & & & & & \\
\hline 10 & .462 & 1.778 & 82.902 & & & & & & \\
\hline 11 & .442 & 1.700 & 84.602 & & & & & & \\
\hline 12 & .396 & 1.522 & 86.124 & & & & & & \\
\hline 13 & .361 & 1.389 & 87.513 & & & & & & \\
\hline 14 & .338 & 1.299 & 88.812 & & & & & & \\
\hline 15 & .313 & 1.203 & 90.015 & & & & & & \\
\hline 16 & .303 & 1.167 & 91.182 & & & & & & \\
\hline 17 & .283 & 1.090 & 92.272 & & & & & & \\
\hline 18 & .278 & 1.069 & 93.341 & & & & & & \\
\hline 19 & .262 & 1.009 & 94.350 & & & & & & \\
\hline 20 & .257 & .989 & 95.339 & & & & & & \\
\hline 21 & .241 & .926 & 96.265 & & & & & & \\
\hline 22 & .223 & .858 & 97.123 & & & & & & \\
\hline 23 & .207 & .798 & 97.921 & & & & & & \\
\hline 24 & .196 & .753 & 98.673 & & & & & & \\
\hline 25 & .187 & .717 & 99.391 & & & & & & \\
\hline 26 & .158 & .609 & 100.000 & & & & & & \\
\hline
\end{tabular}

Note: The numbers from 1 to 26 represented the same items explained in the footnote of table 2.

Table 5 Factor loadings and communalities of items $(n=813)$ 


\begin{tabular}{|c|c|c|c|c|c|}
\hline \multicolumn{2}{|c|}{ Factor } & \multirow{2}{*}{$\begin{array}{c}1 \\
.787\end{array}$} & \multirow[t]{2}{*}{2} & \multirow[t]{2}{*}{4} & \multirow{2}{*}{$\frac{\text { Communality }}{.775}$} \\
\hline 1 & 1.1. Advocate organizational mission and vision to stakeholders. & & & & \\
\hline & 1.2. Oversee a shared direction to achieve organizational mission. & .746 & & & .756 \\
\hline & 1.3. Describe the outcomes related to the allocated resources. & .745 & & & .694 \\
\hline & 1.4. Use resources in a way that maximizes the public well-being. & .722 & & & .699 \\
\hline & 1.5. Establish alliances for joint action at all levels. & .710 & & & .709 \\
\hline & 1.6. Ensure participation of key stakeholders. & 67 & & & .686 \\
\hline & 1.7. Establish a consultation mechanism to heard public voice. & .55 & & & .588 \\
\hline & 1.8. Uphold ethical and moral integrity to serve the public interest. & .535 & & & .536 \\
\hline \multirow[t]{4}{*}{2} & 2.1. Enlist stakeholders to commit resources. & & .712 & & .639 \\
\hline & 2.2. Unite mobilized resources to reach organizational vision. & & .695 & & .652 \\
\hline & 2.3. Model of creativity, innovation and learning. & & .624 & & .585 \\
\hline & 2.4. Show trust and confidence and acknowledge contributions. & & .577 & & .527 \\
\hline \multirow[t]{4}{*}{3} & 3.1. Integrate work structures and work flow. & & .747 & & .766 \\
\hline & 3.2. Coordinate practices with other staff's programs. & & .724 & & .742 \\
\hline & 3.3. Considers the organizational lines of authority for delegation. & & .569 & & .608 \\
\hline & 3.4. Monitor their achievements against the plan, and take lessons. & & .546 & & .595 \\
\hline \multirow[t]{4}{*}{4} & 4.1. Recognize trends, opportunities, and risks. & & & 648 & .626 \\
\hline & 4.2. Articulate the organization's mission, strategy and vision. & & & .630 & .693 \\
\hline & 4.3. Identify client and stakeholder needs and priorities. & & & .611 & .542 \\
\hline & 4.4. Determine key priorities for action. & & & .605 & .653 \\
\hline
\end{tabular}

Table 6 The CR and AVE of the factors indicated on the four factor measurement model $(n=813)$

\begin{tabular}{lcccr}
\hline Parameters & \multicolumn{3}{c}{ Factors } \\
\cline { 2 - 5 } & Compliance with principles & Strategic sensitivity & System building & Contextual thoughtfulness \\
\hline Sum of factor loadings & 5.476 & 2.608 & 2.586 & 2.494 \\
Squared sum of factor loadings & 29.987 & 6.802 & 6.687 & 6.220 \\
\hline Sum of squared factor loadings & 3.807 & 1.712 & 1.704 & 1.556 \\
\hline Sum of error variance & 2.557 & 1.597 & 1.289 & 1.486 \\
CR & .921 & .810 & .838 & .807 \\
AVE & .598 & .517 & .569 & .512 \\
JAVE & .773 & .719 & .775 & .716 \\
\hline
\end{tabular}

Note: squared factor loadings and sum of error variances were calculated by using estimates indicated on figure 2.

Table 7 Parameter estimates of predictors fitted to ordinal logistic regression analysis $(n=813)$ 


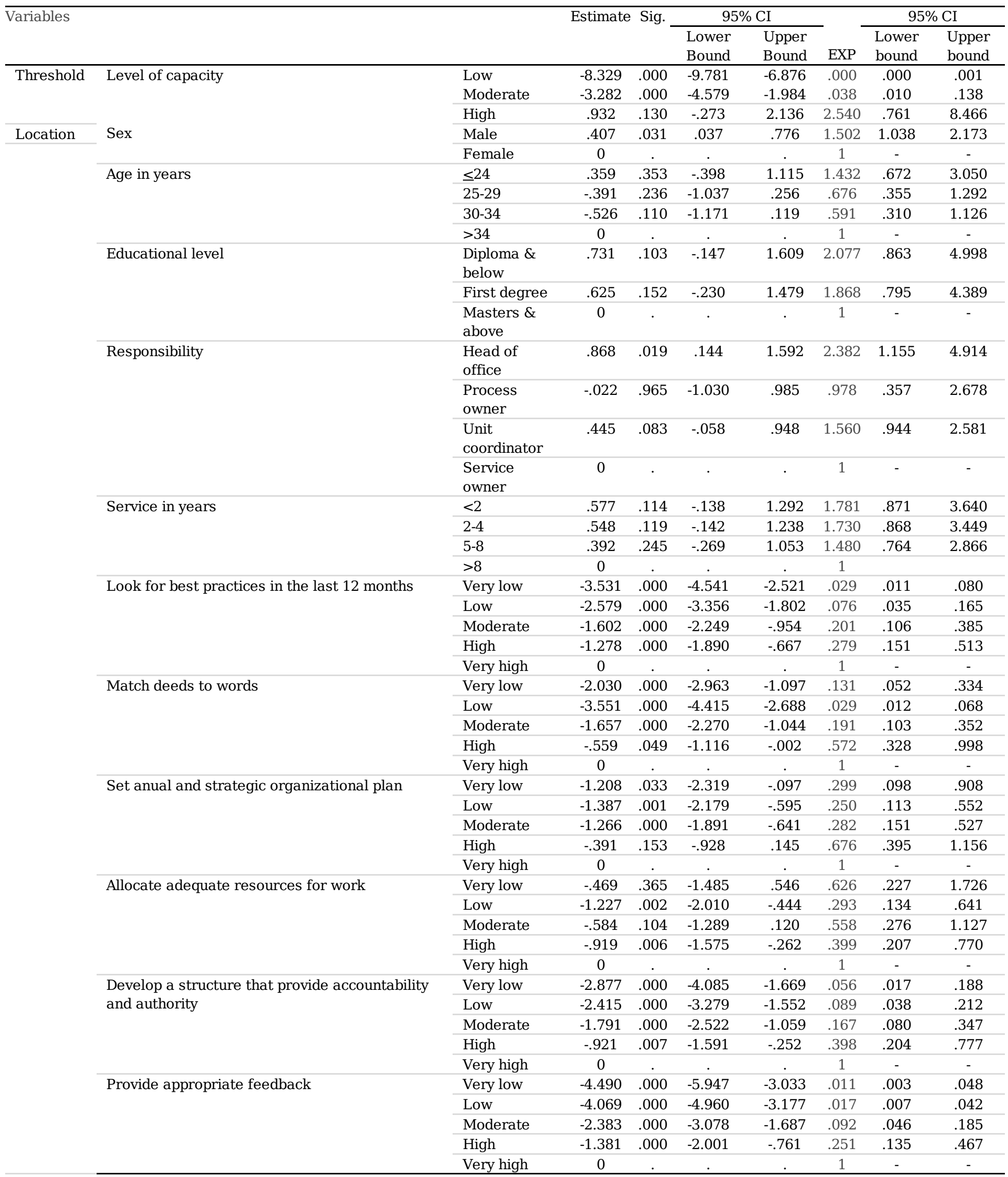




\begin{tabular}{|c|c|c|}
\hline Leading & Managing & Governing \\
\hline हु) scanning & 册 PLANNING & $\mathcal{L}$ cultivate acCountabiLITY \\
\hline$\sum_{0}^{7}$ Focusing & OS ORGANIZING & EE STAKEHOLDERS \\
\hline Aligning/ mobillizing & it IMPLEMENTING & SHARED DIRECTION \\
\hline 先, INSPIRING & $\sqrt{N}$ MONitoring \& EVALUATING & $\frac{\text { EnXXS }}{\text { OPDEN STEWARD RESOURCES }}$ \\
\hline
\end{tabular}

\section{Figure 1}

Integrated health system L+M+G practices model (source: leaders who govern, MSH, 2015)
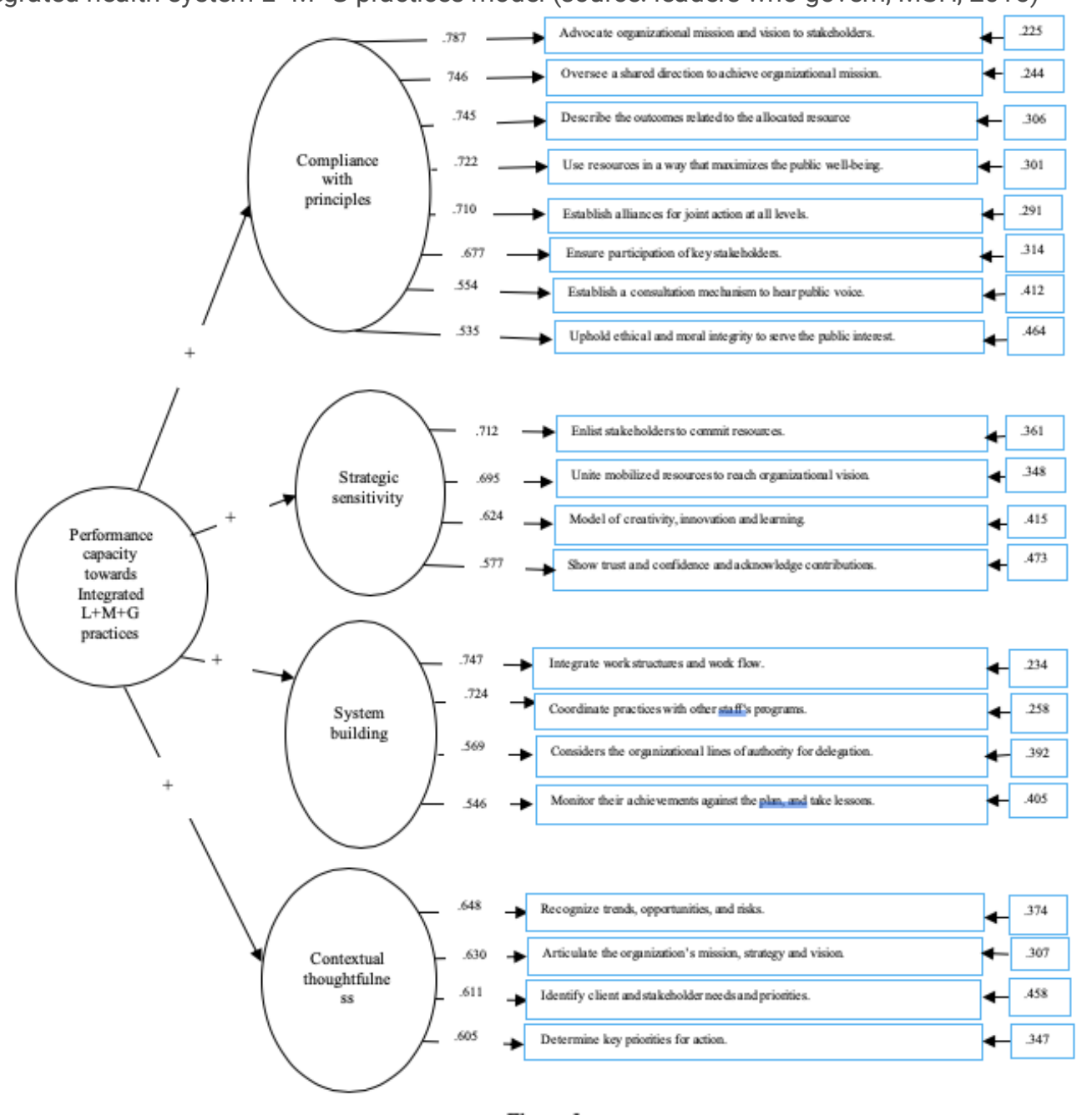


\section{Figure 2}

Measurement model for the performance capacity of the health system workforce towards integrated $L+M+G$ practices

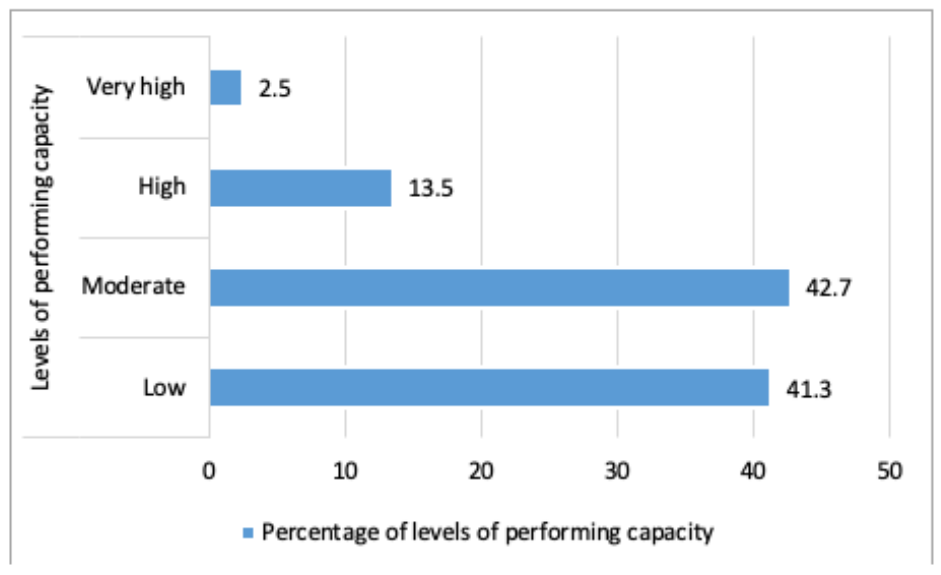

\section{Figure 3}

Performance capacity of the health system workforce towards integrated $L+M+G$ practices 